\title{
REVIEW
}

\section{Challenges in the management of chronic hypoparathyroidism}

\author{
Guido Zavatta ${ }^{1}$ 1 and Bart L Clarke ${ }^{(\mathbb{D} 2}$ \\ 'Department of Medical and Surgical Sciences, University of Bologna, Bologna, Italy \\ ${ }^{2}$ Mayo Clinic, Rochester, Minnesota, USA
}

Correspondence should be addressed to B L Clarke: clarke.bart@mayo.edu

\begin{abstract}
The first adjunctive hormone therapy for chronic hypoparathyroidism, recombinant human parathyroid hormone (1-84) (rhPTH(1-84)) was approved by the FDA in January 2015. Since the approval of rhPTH(1-84), growing interest has developed in other agents to treat this disorder in both the scientific community and among pharmaceutical companies. For several reasons, conventional therapy with calcium and activated vitamin D supplementation, magnesium supplementation as needed, and occasionally thiazidetype diuretic therapy remains the mainstay of treatment, while endocrinologists and patients are constantly challenged by limitations of conventional treatment. Serum calcium fluctuations, increased urinary calcium, hyperphosphatemia, and a constellation of symptoms that limit mental and physical functioning are frequently associated with conventional therapy. Understanding how conventional treatment and hormone therapy work in terms of pharmacokinetics and pharmacodynamics is key to effectively managing chronic hypoparathyroidism. Multiple questions remain regarding the effectiveness of PTH adjunctive therapy in preventing or slowing the onset and progression of the classical complications of hypoparathyroidism, such as chronic kidney disease, calciumcontaining kidney stones, cataracts, or basal ganglia calcification. Several studies point toward an improvement in the quality of life during replacement therapy. This review will discuss current clinical and research challenges posed by treatment of chronic hypoparathyroidism.
\end{abstract}

\section{Key points:}

- Conventional therapy with calcium and activated forms of vitamin D are currently the mainstays of treatment for most patients with chronic hypoparathyroidism.

- Hormone therapy can be administered through FDA-approved once-daily rhPTH(1-84), or off-label multiple-daily injections of teriparatide. The former is the only FDA-approved drug, with safety and efficacy supported by a randomized placebo-controlled trial and open-label long-term extension trial data.

- Twice-daily teriparatide has been used in children safely for up to 10 years.

- New pharmacological options that replace the deficient hormone will likely be available within the next few years.

https://ec.bioscientifica.com

https://doi.org/10.1530/EC-20-0366 (c) 2020 The authors Published by Bioscientifica Ltd

\author{
Key Words \\ hypoparathyroidism \\ - therapy \\ - replacement \\ - calcium \\ - phosphate \\ - parathyroid hormone
}




\section{Introduction}

Over the last 15 years, significant clinical interest has developed in the management of chronic hypoparathyroidism. Until January 2015, chronic hypoparathyroidism was the last major endocrine deficiency without available replacement therapy. Since then a growing body of clinical studies has been published describing the long-term effects of recombinant human parathyroid hormone $\operatorname{rhPTH}(1-84)$, other forms of parathyroid hormone-based therapies, and PTH receptor 1 (PTHR1) agonist therapy.

Although clinical research in chronic hypoparathyroidism is rapidly expanding, treatment of most patients still relies on conventional therapy, largely due to restricted availability of the drugs and high cost. High cost and limited long-term data on the impact of hormone therapy on chronic complications has limited use of $\operatorname{rhPTH}(1-84)$ as a new therapeutic option. In addition, the FDA withdrawal of $\operatorname{rhPTH}(1-84)$ from the market on September 5, 2019, has limited use of intact PTH in the USA over the last several months. The European Medicines Agency did not withdraw this agent, which currently remains available in Europe. Conventional therapy with calcium and active vitamin D supplementation remains the mainstay of treatment for chronic hypoparathyroidism, as recommended by at least three sets of clinical guidelines. Because of this, it remains a challenge for endocrinologists to optimize biochemical parameters of mineral metabolism while minimizing patient symptoms, in an effort to minimize acute and long-term complications of the disease.

Robust evidence regarding the management of hypoparathyroidism in certain clinical situations is still lacking. Pregnancy, chronic kidney disease, and soft tissue calcifications associated with hypoparathyroidism should be managed carefully and with expert guidance, because mechanisms underlying these conditions are incompletely understood. In addition, the management of bone disease in chronic hypoparathyroidism is still being clarified, with conventional therapy thought to possibly worsen the low turnover bone disease, and to contribute to high bone density. Hormone therapy with $\operatorname{rhPTH}(1-84)$ stimulates bone turnover, returning bone turnover and bone density closer to normal, and further increases normal or relatively increased bone density at the lumbar spine, stabilizes hip bone density, and reduces it at the wrist. Producing a PTH analog with finely balanced resorptive and anabolic properties is a significant challenge. Lastly, quality of life (QoL) is significantly adversely affected in chronic hypoparathyroidism, with conventional therapy usually offering moderate benefit. Improving QoL remains a major goal of therapy, although objective quantification and monitoring of patients' burden of symptoms is difficult in practice. European (1) and international guidelines (2) regarding the diagnosis and management of hypoparathyroidism were published in August 2015 and June 2016, respectively. In 2018 the European Society of Endocrinology established the PARAT program, an educational program focusing on parathyroid disorders that aimed to identify unmet scientific and educational needs in chronic hypoparathyroidism (3). The ideas and objectives of the program were presented in the first and second PARAT Workshops, respectively, in September 2018 and June 2019 (https://www.ese-hormones.org/ media/2141/ese-parat-focus-report-2019_v18.pdf). In 2019 a Canadian and international consensus statement on chronic hypoparathyroidism was also released (4).

This review will focus on practical issues regarding the current treatment of chronic hypoparathyroidism, and discuss common challenges in the management of this rare disease within the context of the published guidelines.

\section{Conventional therapy}

The goals of management for chronic hypoparathyroidism presented in the different guidelines are summarized in Table 1. Conventional therapy is first-line therapy and based on calcium and vitamin D supplementation. Dietary calcium is frequently suboptimal in the healthy adult population, and even more likely to be inadequate for managing chronic hypoparathyroidism without calcium supplementation. Calcium can be efficiently administered orally each day in the form of calcium salts. Calcium carbonate and calcium citrate are the most widely available and utilized for this purpose. Calcium carbonate contains twice as much elemental calcium by weight as calcium citrate. Calcium carbonate contains $40 \%$ elemental calcium by weight, whereas calcium citrate contains $21 \%$ elemental calcium by weight. Calcium carbonate is less expensive than calcium citrate. However, calcium carbonate requires stomach acid to absorb well, and it not infrequently causes stomach irritation or intestinal symptoms such as bloating or constipation. Calcium citrate has greater absorption in the small intestine because its bioavailability does not depend on gastric acid (5), and it thereby represents the treatment of choice in patients on proton pump inhibitors 
Table 1 Goals of management for chronic hypoparathyroidism.

\begin{tabular}{|c|c|c|c|}
\hline & $\begin{array}{l}\text { European Society of } \\
\text { Endocrinology (2015) }\end{array}$ & $\begin{array}{l}\text { First International } \\
\text { Conference (2016) }\end{array}$ & $\begin{array}{l}\text { Canadian and International } \\
\text { Consensus (2018) }\end{array}$ \\
\hline Serum calcium (sCa) & $\begin{array}{l}\text { Albumin-adjusted total calcium or } \\
\text { ionized calcium in the lower part } \\
\text { or slightly below the normal } \\
\text { range without symptoms of } \\
\text { hypocalcemia }\end{array}$ & $\begin{array}{l}\text { Prevent signs and symptoms of } \\
\text { hypocalcemia. } \\
\text { Maintain sCa slightly below } \\
\text { normal (no more than } 0.5 \mathrm{ng} / \mathrm{dL} \\
\text { below normal) or in the } \\
\text { low-normal range. } \\
\text { Avoid hypercalcemia. }\end{array}$ & $\begin{array}{l}\text { Not specifically addressed in } \\
\text { general, but in pregnancy should } \\
\text { be kept in the low- to mid- } \\
\text { normal reference range. Avoid } \\
\text { hypercalcemia. }\end{array}$ \\
\hline Serum phosphorus & Within the reference range & Not specifically addressed & Within the reference range. \\
\hline 24 h urinary calcium & $\begin{array}{l}\text { Within the sex-specific reference } \\
\text { range (<300 mg/24-h in men; } \\
\text { <250 mg/24-h in women; or } \\
\text { <4 mg/kg/24-h in both sexes) }\end{array}$ & Avoid hypercalciuria. & Avoid hypercalciuria. \\
\hline $\begin{array}{l}\text { Calcium } \times \text { phosphate } \\
\text { product }\end{array}$ & $<55 \mathrm{mg}^{2} / \mathrm{dL}^{2}$ & $<55 \mathrm{mg}^{2} / \mathrm{dL}^{2}$ & $<55 \mathrm{mg}^{2} / \mathrm{dL}^{2}$ \\
\hline 25-hydroxyvitamin D & >20 ng/mL seems reasonable & No specific suggestion & $\begin{array}{l}\text { Normal (30-50 ng/mL), also in } \\
\text { pregnancy }\end{array}$ \\
\hline Diet & $\begin{array}{l}\text { Adequate daily calcium intake. } \\
\text { If hypercalciuria: low-sodium diet } \\
\text { and reduce calcium intake } \\
\text { If hyperphosphatemia: low- } \\
\text { phosphate diet. }\end{array}$ & $\begin{array}{l}\text { Dietary calcium optimized. } \\
\text { Low-phosphate and low-sodium } \\
\text { diet if necessary to manage } \\
\text { hyperphosphatemia and } \\
\text { hypercalciuria, respectively. }\end{array}$ & $\begin{array}{l}\text { Low-phosphate diet (low intake of } \\
\text { meat, eggs, colas and dairy) may } \\
\text { be implemented as needed on } \\
\text { an individual basis. A low-salt } \\
\text { diet is also helpful as it lowers } \\
\text { renal calcium losses. }\end{array}$ \\
\hline
\end{tabular}

(PPIs) or those with achlorhydria. To achieve a sufficient dose of elemental calcium, calcium citrate usually requires a greater number of tablets each day. Commercial calcium preparations are required to show their elemental calcium content on their labels. Individual doses of calcium ideally should not exceed 500 to $600 \mathrm{mg}$, because higher doses are not as efficiently absorbed from the intestine and might be more likely to cause adverse gastrointestinal effects (6).

Activated $1 \alpha$-hydroxylated vitamin $\mathrm{D}$ analogs are essential for adequate calcium absorption, with 1,25-dihydroxyvitamin D (calcitriol) and 1 $\alpha$-calcidol being most commonly employed. Calcitriol is typically given in a dose ranging from $0.5-2.0 \mu \mathrm{g}$ per day, while $1 \alpha$-calcidol is usually given as 1.0-4.0 $\mu \mathrm{g}$ daily (7). The half-life of calcitriol is $4-6 \mathrm{~h}$, thereby requiring once or twice daily administration. The guidelines recommend maintaining serum 25-hydroxyvitamin D above at least $20 \mathrm{ng} / \mathrm{ml}$ with or without supplementation. Experts in some countries favor using activated $1 \alpha$-hydroxylated vitamin D analogs as the primary therapy, and supplement this with calcium as needed. Experts in other countries favor using calcium as the primary therapy, and supplement this with activated $1 \alpha$-hydroxylated vitamin D analogs as needed. These differences may be more than philosophical, and may potentially lead to different rates of complications.

Thiazide diuretics reduce urinary calcium excretion and can be used as adjunctive therapy, although high salt intake may override the potential benefits of these agents on urinary calcium (8). If thiazides are used, serum magnesium and potassium should be checked periodically. It is important to note that thiazides should not be administered to patients with autosomal dominant hypocalcemia as they may worsen hypomagnesemia. Additionally, patients with adrenal insufficiency should avoid them as they worsen urinary sodium loss and may cause hypotension.

Phosphate binders or low phosphorus diets may be required to control serum phosphorus in patients with significant hyperphosphatemia. Serum phosphorus may be particularly difficult to control in some patients without parathyroid hormone analogs.

The biochemical challenges in the management of chronic hypoparathyroidism are caused equally by the lack of parathyroid hormone and by the undesirable biochemical abnormalities produced by non-physiologic supplementation with calcium and activated vitamin D to primarily prevent hypocalcemia. In spite of best efforts with the available supplements, fluctuations of serum calcium, hyperphosphatemia, and hypercalciuria are commonly observed in clinical practice.

\section{Adjunctive therapy with available PTH analogs}

Mimicking the pharmacokinetics of the missing or insufficiently secreted native parathyroid hormone represents a difficult challenge for all replacement therapies.
This work is licensed under a Creative Commons Attribution-NonCommercial 4.0 International License. ded from Bioscientifica,com at 04/26/2023 09:52:36 AM via free access 
Pivotal studies on the physiology of PTH secretion in humans date back to the 1980s. PTH was shown to be secreted in two phases, with a predominant tonic mode, and approximately $25 \%$ secreted as superimposed pulses (9). The frequency and amplitude of pulses is increased by acute reductions of ionized calcium, with a return to equilibrium about $2 \mathrm{~h}$ following a PTH pulse (10). A circadian rhythm of PTH has also been described, with a pronounced peak in the early morning, a nadir in the late morning, and a second lower peak in the afternoon, likely related to daily nutritional mineral changes (11). Preservation of fluctuations in PTH secretion seems essential to maintenance of normal bone turnover.

Ideally, replacement therapy in chronic hypoparathyroidism should restore a physiologic pattern of PTH secretion. Some PTH analogs and small molecules interact with the PTH1 receptor to achieve long-lasting post-receptor signaling. Full understanding of the pharmacokinetics and pharmacodynamics of the available therapies and therapies under development remains key to optimizing replacement therapy.

\section{PTH(1-34)}

Winer et al. first evaluated daily administration of teriparatide (PTH(1-34)) in chronic hypoparathyroidism. Winer et al. used a different preparation of lyophilized human PTH(1-34) from Bachem, Inc., rather than teriparatide (Forteo®, Eli Lilly), which was FDAapproved for osteoporosis. Winer et al. demonstrated that PTH(1-34) reduced urinary calcium excretion while maintaining serum calcium within the normal range, as compared with treatment with calcitriol and calcium (12). However, the effects of once-daily $\operatorname{PTH}(1-34)$ wore off after approximately $12 \mathrm{~h}$, resulting in serum calcium levels falling below the normal range in some patients. Moreover, single-daily administration of teriparatide had anabolic effects on trabecular bone and, while promising, appeared to be far from the ideal replacement therapy.

Subsequently, Winer et al. compared once-daily vs twice daily PTH(1-34) (13). The latter of which lowered the tendency toward low serum calcium levels during the second half of the day. The twice-daily regimen maintained serum calcium concentrations in a narrower range with a much lower dose of PTH(1-34). The increase in alkaline phosphatase was noted to be significantly lower with twice-daily administration. Although urine calcium was lower than when compared with conventional treatment, there was no difference between once and twice-daily PTH(1-34) regarding this endpoint.
In the attempt to avoid peaks in serum calcium and consequently reduce the overall filtered calcium load, Winer et al. compared continuous $\mathrm{PTH}(1-34)$ delivery by insulin pump with twice daily administrations of PTH(1-34) (14). As expected, infusion therapy with PTH(1-34) produced less variability in serum calcium during the day and a more than 50\% reduction in urine calcium. As compared with twice-daily injections, normal serum calcium levels could be maintained with the total daily dose of PTH reduced by $65 \%$. Infusion therapy also impacted favorably on magnesium levels, leading to reduced need for magnesium supplements. Pump delivery also normalized bone turnover markers. Interestingly, twice daily injections seemed to have greater ability to stimulate $1 \alpha$-hydroxylase, since 1,25 -dihydroxyvitamin D values were higher during 24 -h profiles. The authors concluded that pump delivery of PTH(1-34) provided the closest approach to normal physiology in the management of chronic hypoparathyroidism.

Although not approved for treatment of chronic hypoparathyroidism, there is promising long-term data with PTH(1-34) treatment in adults and children. Palermo et al. (15) tested twice-daily teriparatide (Forteo ${ }^{\circledR}$, Eli Lilly) in a prospective open-label study in 42 patients with postsurgical hypoparathyroidism over 2 years. The study showed that teriparatide was safe and effective in maintaining stable serum calcium over time, while reducing the requirement for calcium and active vitamin D supplements. Calcium $\mathrm{x}$ phosphate product was slightly increased, probably due to markedly improved serum calcium levels compared to baseline, while phosphate levels trended downward and were significantly reduced by the end of the study compared to baseline. The study did not observe a reduction in urinary calcium, probably the result of the higher renal calcium filtered load during treatment and the shortterm effects of teriparatide on the renal tubule. Similar results were reported by Winer et al. in a smaller 3-year open label trial comparing twice daily PTH(1-34) with conventional treatment (16). Teriparatide also seemed to improve some mental and physical aspects of patient quality of life (17), although lack of a control group limited the interpretation of study outcomes. Long-term data have recently been published with teriparatide in children $(18,19)$ with nonsurgical hypoparathyroidism. Although it is not yet clear whether PTH(1-34) is able to prevent long-term complications in patients with chronic hypoparathyroidism, replacement therapy with multiple daily injections of teriparatide appears to be safe and effective for up to 10 years.

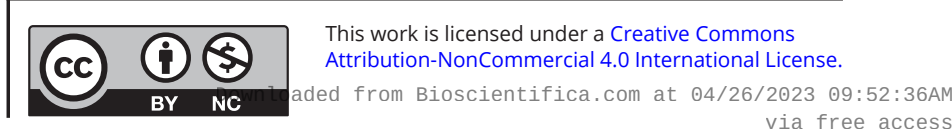


Low urine citrate concentrations have been reported as an untoward effect of multiple daily teriparatide injections (20). Gafni et al. described a negative association between urine citrate and total daily dose of $\mathrm{PTH}(1-34)$, which led to a higher urinary calcium/urinary citrate ratio over the course of treatment (20). This biochemical alteration suggested that more frequent monitoring for renal complications such as nephrolithiasis or nephrocalcinosis may be appropriate during teriparatide replacement therapy.

\section{rhPTH(1-84)}

The FDA approved once-daily $\operatorname{rhPTH}(1-84)$ (Natpara®, Shire/Takeda) for adjunctive therapy of chronic hypoparathyroidism in adults in January 2015. In 2017 the drug received approval by the EMA (Natpar®, Shire/ Takeda) and is now commercially available in some European countries. Of note, Natpara ${ }^{\circledR}$ was recalled by the FDA on September 5, 2019, due to technical problems with the delivery device that led to rubber particles being found in the cartridge liquid. The recall in the USA is expected to remain in force through early 2021. Exceptional patients with life-threatening symptoms who continued to take Natpara through the date of the recall may continue to receive Natpara through the Special Use Program established by Shire/Takeda. Patients enrolled in this program are instructed to take one daily injection from each 2-week cartridge and then to discard the remainder of the cartridge. The EMA declined to recall Natpar ${ }^{\circledR}$, so this medication remains available in Europe. $\operatorname{rhPTH}(1-84)$ remains the only approved adjunctive therapy for chronic hypoparathyroidism.

Studies on the pharmacokinetics of once-daily administration of $\operatorname{rhPTH}(1-84)(21,22)$ showed that the drug is detectable in plasma for up to $12-16 \mathrm{~h}$ (Fig. 1). The half-life of the drug averages $2-3 \mathrm{~h}$. However, the biochemical effects on serum calcium and other minerals last for up to $24 \mathrm{~h}$. The study by Sikjaer et al. (22) showed that serum ionized calcium levels over $24 \mathrm{~h}$, assessed by analysis of area under the curve (AUC) and peak serum concentration, positively correlated with the amount of PTH released into the circulation over time and not with peak PTH levels when injected into the thigh but not the abdomen, thus supporting the use of the thigh as the preferred site of injection because of the slower absorption rate compared to the abdomen.

It remains unclear why PTH(1-34) requires two or three administrations during the day, compared with a single injection of $\operatorname{rhPTH}(1-84)$, given that these peptides have similar half-lives. Longer uptake time from subcutaneous

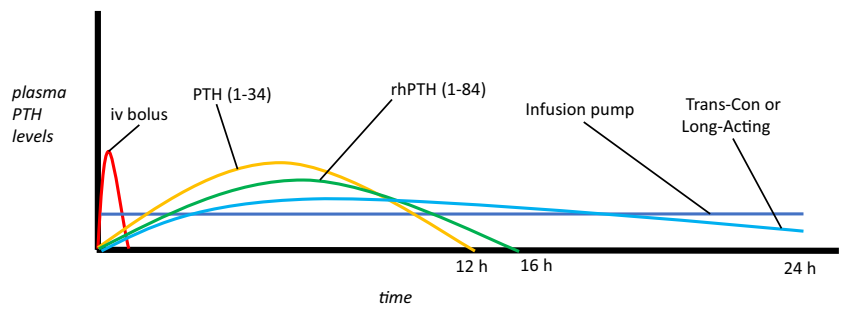

Figure 1

Native PTH half-life in the blood is $2-5 \mathrm{~min}$. Subcutaneous preparations of PTH analogs are devised to prolong the half-life of the molecule, thereby increasing their biological activity. When PTH is infused through a subcutaneous insulin pump, its blood levels remain constant throughout the day. PTH(1-34) and PTH(1-84) have similar kinetics and are characterized by a variable peak. Trans-Con or other long-acting PTH molecules are designed to have longer half-lives and a persistent biological effect. Figure created by Dr Guido Zavatta from published data $(12,13,14,21,46)$.

tissue depots or greater duration of biological activity of rhPTH(1-84) may both be implicated (23).

The REPLACE study was the pivotal 6-month phase 3 clinical trial that led to FDA approval of $\operatorname{rhPTH}(1-84) 50$, 75, and $100 \mu \mathrm{g}$ doses (24). The results of this trial were subsequently confirmed and expanded upon during the open-label 6-year RACE study $(25,26)$. The REPEAT (27) study evaluated low-dose 25 and $50 \mu \mathrm{g}$ daily doses of rhPTH(1-84) over 2 months. The Columbia group $(28,29)$ has published long-term studies of $\operatorname{rhPTH}(1-84)$ safety and efficacy while following a cohort of patients for up to 8 years.

The phase 3 24-week randomized, double-blind, placebo-controlled REPLACE trial demonstrated that 53\% of patients who received $\mathrm{rhPTH}(1-84)$ were able to reduce both oral calcium and vitamin $\mathrm{D}$ supplements by more than $50 \%$ from baseline. Only $2 \%$ of those who received conventional treatment met this endpoint $(P<0.0001)$. While serum calcium levels remained stable and in the normal range, phosphate concentrations and the calcium $\mathrm{x}$ phosphate product decreased rapidly within the first week and remained significantly lower compared with conventional treatment throughout the study period (30). Although data are not yet available regarding the incidence of complications during long-term rhPTH(1-84) replacement, the observed reduction in serum phosphate concentrations may be crucial in preventing softtissue calcification, nephrocalcinosis, cataracts, or basal ganglia calcifications. The REPLACE study was unable to demonstrate a reduction in urinary calcium excretion over the 6-month trial period.

The open-label 6-year extension (25) RACE study described a gradual reduction in urinary calcium progressively throughout the 72-month follow-up

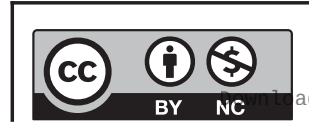



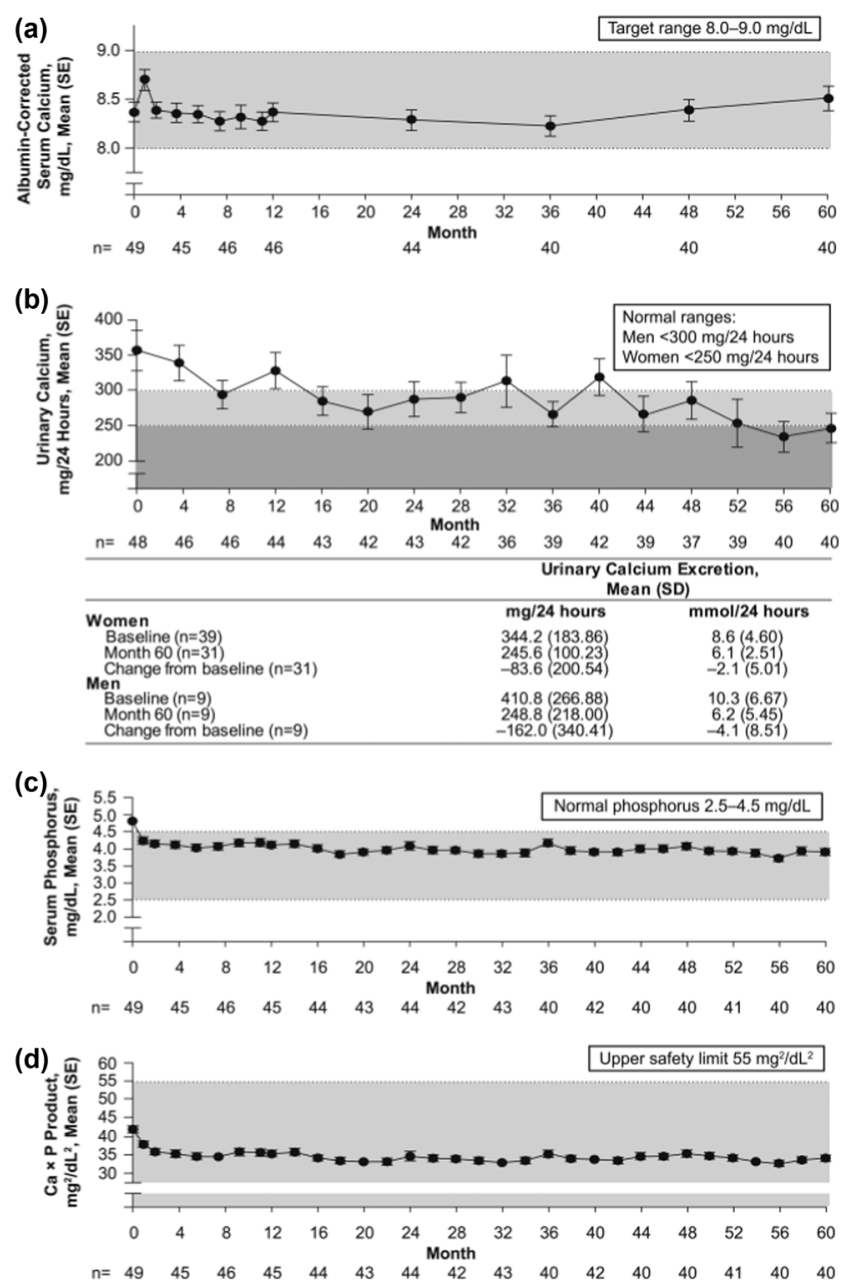

Figure 2

Results from RACE trial (26). Changes in (A) albumin-corrected serum calcium level, (B) urinary calcium excretion, (C) serum phosphorus level, and (D) Ca $\times$ P product over time during therapy with rhPTH(1-84) over a 5-year follow-up period. Reproduced, under the terms of the original CC BY licence, from Mannstadt et al. (2019) Safety and efficacy of 5 years of treatment with recombinant human parathyroid hormone in adults with hypoparathyroidism, Journal of Clinical Endocrinology and Metabolism, volume 104, pages 5136-5147.

period (Fig. 2), with urinary calcium in the normal range by the fifth year of the trial. RACE also demonstrated that renal function remained stable during the 6-year treatment period with 50,75 , or $100 \mu$ g daily doses of rhPTH(1-84). A recent retrospective study (31) confirmed the ability of rhPTH(1-84) to maintain renal function stable during a 5-year period, by comparing subjects enrolled in four open-label long term trials (NCT00732615, NCT01268098, NCT01297309 and NCT02910466) with patients taken from a historical cohort and treated with conventional therapy. The subjects on conventional therapy experienced a progressive decline in eGFR, as opposed to patients receiving $\operatorname{rhPTH}(1-84)$, in whom
eGFR was preserved. The difference in the annual change in eGFR was $-1.7 \mathrm{~mL} / \mathrm{min} / 1.73 \mathrm{~m}^{2}$ between the control group and $\operatorname{rhPTH}(1-84)$.

The RELAY (32) study investigated 25 and $50 \mu$ g doses of rhPTH(1-84) over 2 months and concluded that these lower doses may be adequate for a subset of patients.

Real-world longitudinal data on the effects of rhPTH(1-84) are being accumulated in the multinational PARADIGHM registry study. This study is actively recruiting a prospective observational registry of up to 900 patients with chronic hypoparathyroidism receiving clinical care with conventional therapy or $\operatorname{rhPTH}(1-84)$ over 10 years (33).

Most studies have demonstrated subjective improvement in patient quality of life with $\operatorname{rhPTH}(1-84)$ compared to controls receiving conventional therapy when evaluated using the SF-36 questionnaire $(29,34)$. However, two studies did not show significant improvement in the overall SF-36 score, when rhPTH(1-84) was compared with placebo $(35,36)$. In one study $(35)$, several domains of the SF-36 questionnaire (physical component summary score, body pain, general health and vitality) were significantly improved in the rhPTH(1-84) cohort. Also, another study (36) did not show any benefit of rhPTH(1-84) on muscle function and postural stability during a 6-month treatment course with a fixed dose of $100 \mu \mathrm{g} / \mathrm{day}$, compared with placebo. This study failed to show an improvement in quality of life as assessed by the SF-36. The authors suggested that a high frequency of hypercalcemia ( 21 out of 29 subjects in the group receiving rhPTH(1-84) had two or more episodes of hypercalcemia) may have compromised the potential beneficial effects of PTH therapy on quality of life. Overall, it seems that patients with lower SF-36 scores at baseline before treatment and taking a greater number of daily supplement tablets appeared to benefit the most from adjunctive therapy. Several recently developed disease-specific questionnaires for chronic hypoparathyroidism (37) are undergoing validation and may improve the identification and monitoring of specific symptoms attributed to this condition.

\section{Considerations during use of available PTH analogs}

Discontinuation of available PTH analogs for various reasons may occasionally lead to unexpected hypocalcemia. The 4-week follow-up period of the REPLACE clinical trial showed that patients who discontinued rhPTH(1-84) were more likely to experience hypocalcemia when resuming baseline calcium and vitamin D supplements, compared

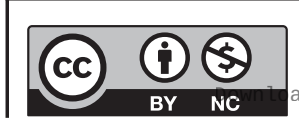

This work is licensed under a Creative Commons Attribution-NonCommercial 4.0 International License. ded from Bioscientifica.com at 04/26/2023 09:52:36AM 
with those who had been treated with conventional therapy only during the 6-month clinical trial $(31 \%$ vs 9\%) (24). Gafni et al. subsequently evaluated this potential issue in another study in patients receiving $\mathrm{PTH}(1-34)$ (38). Two out of nine patients who had been receiving PTH(1-34) two or three times daily developed severe hypocalcemia $(6.3 \mathrm{mg} / \mathrm{dL}$ and $6.6 \mathrm{mg} / \mathrm{dL})$ within several days after withdrawal from teriparatide. In both patients there was an abrupt transition to calcium and calcitriol at their pre-PTH(1-34) doses. In light of these two adverse events, the remaining seven patients were treated with calcium and calcitriol supplements at doses two to three times higher than their baseline pre-PTH(1-34) doses, with a simultaneous gradual decrease in their $\mathrm{PTH}(1-34)$ dose over several weeks, with close monitoring of their serum biochemistries. The occurrence of post-withdrawal hypocalcemia resembles what occurs during hungry bone syndrome (HBS) after parathyroid surgery for hyperparathyroidism. Post-withdrawal hypocalcemia may be driven by rapid modifications in bone turnover. Gafni et al. observed a rapid reduction in bone resorption markers associated with a slower reduction in bone formation markers, which remained moderately increased for some time after discontinuation of $\operatorname{rhPTH}(1-34)$. Increases in bone mineral density observed after discontinuation of PTH(1-34) support the hypothesis that bone formation continues for a time, with disproportionately high demand for serum calcium by the bone. Although the incidence of this phenomenon is unknown, the possibility of hypocalcemia during withdrawal of PTH analog treatment in chronic hypoparathyroidism must be kept in mind.

The effects of PTH(1-34) and rhPTH(1-84) on serum calcium are produced by different mechanisms from those affecting urinary calcium. PTH analogs directly mediate calcium reabsorption by the kidneys, while serum calcium levels are also determined by calcitriol-dependent intestinal calcium absorption, and therefore less directly affected by plasma PTH concentrations. Single daily injections of rhPTH(1-84), or two or three daily injections of PTH(1-34), produce relatively variable levels of plasma PTH over the 24-h interval. Therefore, unless the half-life of the PTH analog is prolonged, tonic effects of PTH on the renal tubule will be difficult to achieve, resulting in a reduced effect on renal tubular calcium reabsorption when PTH plasma levels start to decline. A clinical trial of twice daily $\mathrm{rhPTH}(1-84)$ (PARALLAX trial) has recently been completed, but results have not yet been presented (ClinicalTrials.gov Identifier: NCT02781844).

The cost of conventional therapy is negligible compared to the financial burden of PTH analog therapy. Because of this, it is reasonable for the clinician to take pharmaco-economic issues into consideration (39), and to reserve adjunctive therapy for patients who will benefit the most. Table 2 illustrates the indications for therapy in the current guidelines and expert consensus statements regarding starting of adjunctive therapy in patients with chronic hypoparathyroidism.

\section{Safety of adjunctive therapy}

The occurrence of osteosarcoma was demonstrated in Fischer 344 rats with prolonged administration of high doses of PTH(1-34), rhPTH(1-84), and PTH-related peptide $(40,41)$. Following the long experience with teriparatide as a treatment for osteoporosis approved in 2002,

Table 2 When to consider replacement therapy.

\begin{tabular}{|c|c|}
\hline European Society of Endocrinology (2015) & First International Conference (2016) \\
\hline \multirow{3}{*}{$\begin{array}{l}\text { Recommended against routine use of } \\
\text { replacement therapy with PTH or PTH } \\
\text { analogs. } \\
\text { (rhPTH(1-84) not approved in Europe } \\
\text { at the time of guidelines) }\end{array}$} & $\begin{array}{l}\text { Inadequate control of the serum } \\
\text { calcium (intercurrent illness, } \\
\text { compliance, absorption). }\end{array}$ \\
\hline & $\begin{array}{l}\text { Oral calcium }>2.5 \mathrm{~g} \text { daily or calcitriol } \\
>1.5 \mu \mathrm{g} \text { daily or } 1 \text {-alpha vitamin } \mathrm{D} \\
>3.0 \mu \mathrm{g} \text { daily }\end{array}$ \\
\hline & $\begin{array}{l}\text { Hypercalciuria, renal stones, } \\
\text { nephrocalcinosis, stone risk or } \\
\text { reduced eGFR ( }<60 \mathrm{ml} / \mathrm{min}) \text {. } \\
\text { Hyperphosphatemia and/or calcium- } \\
\text { phosphate product }>55 \mathrm{mg}^{2} / \mathrm{dL}^{2} \text {. } \\
\text { A gastrointestinal tract disorder that is } \\
\text { associated with malabsorption. } \\
\text { Reduced quality of life. }\end{array}$ \\
\hline
\end{tabular}

Canadian and International Consensus (2018)

Inadequate control of serum calcium. Noncompliance with multiple daily dosing of supplements.

Oral calcium or vitamin D medications required to control serum calcium or symptoms that exceed $2.5 \mathrm{~g}$ of calcium or $>1.5 \mu \mathrm{g}$ of calcitriol per day

Hypercalciuria, renal stones, nephrocalcinosis, stone risk or reduced eGFR ( $<60 \mathrm{ml} / \mathrm{min})$.

Hyperphosphatemia and/or calcium-phosphate product $>55 \mathrm{mg}^{2} / \mathrm{dL}^{2}$.

May be of value in individuals who have malabsorption.

May reduce quality of life, further studies needed. 
there is not a human safety concern with the current single-daily $20 \mu$ g dosing regimen (7). $\operatorname{rhPTH}(1-84)$ was approved by the FDA in January 2015 with a black box warning, but no restriction on duration of use.

\section{Bone effects of PTH analogs in chronic hypoparathyroidism}

PTH(1-34) significantly stimulates bone turnover in women with postmenopausal osteoporosis. An early increase in bone formation markers (e.g. bone specific alkaline phosphatase and P1NP) is followed by a subsequent increase in bone resorption markers (e.g. beta-CTx) (42). Evidence regarding the impact of PTH analogs on BMD in chronic hypoparathyroidism is limited by the small size and relatively short duration of studies, but trabecular bone appears to be maintained or slightly increased, while cortical bone tends to decrease $(16,43)$. The RACE study showed that bone density increased at the lumbar spine and total hip, remained stable at the femoral neck, and decreased at the $1 / 3$ distal radius. Cortical porosity increases with both PTH(1-34) and rhPTH(1-84) (44). Data on bone outcomes with $\mathrm{rhPTH}(1-84)$ longer than 8 years are not yet available in adults. No bone-related adverse events have been reported in children to date $(18,19)$.

Recent data on BMD and skeletal microstructure with 4 continuous years of $\mathrm{rhPTH}(1-84)$ have been published (45). The majority of patients (64\%) took $\operatorname{rhPTH}(1-84)$ $100 \mu \mathrm{g}$ every other day for most of the study. The study showed an increase in BMD at the lumbar spine and femoral neck, with declines at the total hip and ultradistal radius. The study also showed that rhPTH(1-84) increased cortical porosity. The initial decrease in cortical thickness with PTH analog treatment is thought to represent a return toward more normal bone structure. Longer-term therapy with PTH analogs may cause continued decreases in cortical thickness as long as therapy is continued, but the significance of this is not yet certain. There are no fracture data yet in patients treated with long-term therapy.

\section{New pharmacologic agents under development}

Injectable preparations

\section{Trans-Con PTH 1-34}

Trans-Con PTH 1-34 is PTH(1-34) transiently conjugated to a branched polymer of methoxypolyethylene glycol (mPEG) through a proprietary Trans-Con linker.
The mPEG polymer works as a carrier and shields the active molecule from degradation, while the TransCon linker allows a gradual release of active PTH(1-34) with an auto-cleavage reaction controlled by $\mathrm{pH}$ and temperature. This pharmacokinetic innovation enables PTH(1-34) to have a half-life of approximately $60 \mathrm{~h}$ (46). A phase 1 clinical trial demonstrated that Trans-Con PTH has a potent and sustained effect on serum calcium, renal calcium reabsorption, and urinary phosphate secretion without evidence of anabolic effects on bone (47). The drug is currently under evaluation in a phase 2 clinical trial, with preliminary results recently presented in abstract form, with a recent decision to further extend this study (48). A global phase 3 clinical trial is anticipated.

\section{Other long-acting versions of PTH}

There are a number of PTH analog molecules with prolonged actions which may be tested in clinical trials in the near future. Attaching polyethylene glycol (PEG) to PTH(1-34) with a linker molecule allows a significant increase in the biological activity of the active molecule (49). In mice, after injections of PEG-PTH, calcium levels were still elevated at $48 \mathrm{~h}$ and did not return to baseline levels until $96 \mathrm{~h}$. This molecule remains in clinical development.

Biological activity of PTH can be further prolonged by focusing on the interaction between PTH and the PTHR1 receptor. In models of thyroparathyroidectomized rats and normal monkeys, after modifying the amino acid sequence of human PTH(1-84) and PTHrp, Shimizu et al. (50) obtained a stronger and longer lasting effect on the PTHR1 receptor without changing the pharmacokinetic characteristics. Other long-acting PTH analogs were injected in mice with acquired hypoparathyroidism and shown to have more potent effects than teriparatide (51). Another compound (LY627-2K) initially developed to reduce daily injections in postmenopausal osteoporosis treatment may be repurposed for treatment of chronic hypoparathyroidism (52).

AZP-3601 is a PTH(1-84) analog designed by investigators at the Massachusetts General Hospital and being developed by Amolyt Pharmaceuticals in Lyon, France. AZP-3601 potently interacts with a specific configuration of the PTHR1 receptor, and holds the receptor in an active conformation that results in prolonged biological effects. No published clinical data are available yet (information obtained from: https:// amolytpharma.com/\#our-programs).
This work is licensed under a Creative Commons Attribution-NonCommercial 4.0 International License. ded from Bioscientifica.com at 04/26/2023 09:52:36AM via free access 


\section{Oral small molecules}

An oral agent for the treatment of chronic hypoparathyroidism may be helpful for patients not wishing to take injectable therapy. A phase $1 \mathrm{~b}$ clinical trial (NCT04209179) is underway to test an oral small molecule (PCO371) with PTHR1 receptor agonist properties being developed by Chugai Pharmaceuticals in Japan. This new compound has shown promising results in vitro and in animal models (53). A phase 2 clinical trial evaluating oral PTH(1-34) was completed in 2019 (NCT02152228), but these results have not yet been published.

\section{Special considerations}

\section{Pregnancy}

Management of chronic hypoparathyroidism during pregnancy represents a serious challenge for endocrinologists because there are scarce data on this topic. Treatment decisions are usually made following guidance based on expert opinion, bearing in mind the physiologic changes in calcium metabolism that typically occur during gestation. An expert consensus statement was released (4) followed by evidence-based recommendations (54). Calcium and activated vitamin D supplements are the mainstay of treatment for chronic hypoparathyroidism during pregnancy. Both maternal hypocalcemia and hypercalcemia should be avoided due to the risks of secondary hyperparathyroidism or hypocalcemia in the fetus, respectively. PTHrp is produced by the placenta and breast tissue of the mother and may be protective against hypocalcemia, as this stimulates $1 \alpha$-hydroxylase (CYP27b1) in the kidneys, leading to greater production of 1,25-dihydroxyvitamin D. PTHrp, prolactin, estradiol, and placental lactogen all enable levels of 1,25-dihydroxyvitamin $\mathrm{D}$ to increase two- or three-fold during pregnancy. Nonetheless, it is difficult to anticipate the doses of calcium and calcitriol supplementation necessary to maintain normal serum calcium levels in the mother. Patients should be followed closely, at least every 3 weeks, with periodic adjustments of calcium and vitamin D supplements. Total calcium should be maintained in the low- to mid-normal reference range. Albumin concentrations may be lowered because of physiologic volume expansion during pregnancy. Hypercalciuria may worsen due to increased renal filtered load of calcium. Adjunctive therapy with PTH analogs has not been evaluated during pregnancy (FDA Category C drug). Like hydrochlorothiazide (FDA Category B drug), these agents should generally be avoided during pregnancy, unless benefit is felt to outweigh potential risks to the fetus or mother. There are no published guidelines on management of pregnancy in patients with hypoparathyroidism. Patients planning pregnancy are normally advised to stop PTH analogs before becoming pregnant, unless the risks of stopping therapy are felt to be greater than the risks of continuing therapy. Fetal risk cannot be ruled out. Patients are normally successfully managed during pregnancy with conventional therapy.

\section{Hypocalcemic crisis}

Acute hypocalcemia may be life-threatening in patients with chronic hypoparathyroidism, especially if it develops rapidly (e.g. after neck exploration surgery with inadequate calcium or vitamin D intake). An intravenous infusion of calcium gluconate is typically recommended for patients in crisis under continuous ECG monitoring, since overly rapid correction may provoke cardiac rhythm disturbances leading to cardiac arrest. The initial recommended dose is commonly calcium gluconate 1-2 g (90-180 elemental calcium) diluted in $50 \mathrm{~mL}$ of $5 \%$ dextrose or normal saline over 10-20 min. A slower infusion should then be started at $0.5-1.5 \mathrm{mg} / \mathrm{kg}$ body weight $/ \mathrm{h}$ and given for at least 8-10 h. Calcium gluconate contains $93 \mathrm{mg}$ elemental calcium per $10 \mathrm{~mL}$ of solution at this concentration. Monitoring of serum calcium should be performed every 4-6 h (7). When patients also have acidosis, it is very important to address the hypocalcemia first before correcting the acid-base disturbance, because doing the opposite will further lower ionized calcium. Unlike the use of insulin in hyperglycemic crisis, subcutaneous PTH analogs should not be given to improve acute hypocalcemia in hypoparathyroidism, because the route of administration by subcutaneous injection may delay the onset of action of the drug. However, it is interesting to note that $\mathrm{PTH}(1-34)$ may prevent post-thyroidectomy acute hypocalcemia when given $4 \mathrm{~h}$ after surgery (55), and subsequently every $12 \mathrm{~h}$ until hospital discharge. In the THYPOS trial, subjects with intact PTH level below $10 \mathrm{pg} / \mathrm{mL} 4 \mathrm{~h}$ after thyroidectomy were randomly assigned to receive $\mathrm{PTH}(1-34)$ or standard clinical care, resulting in higher median calcium level ( 8.5 vs 7.8$)$ at hospital discharge and shorter hospitalization (2 days vs 3 days) in the $\mathrm{PTH}(1-34)$ group.

\section{Autosomal dominant hypocalcemia type 1}

Gain of function mutations in the calcium-sensing receptor (CaSR) are responsible for autosomal
This work is licensed under a Creative Commons Attribution-NonCommercial 4.0 International License. ded from Bioscientifica.com at 04/26/2023 09:52:36AM via free access 
dominant hypocalcemia type $1(\mathrm{ADH} 1)$, a rare form of hypoparathyroidism with profound hypocalcemia and often intractable hypercalciuria which leads to nephrocalcinosis. Adjunctive therapy is often the treatment of choice for this condition, with most of the supporting data coming from trials of twice daily teriparatide. By increasing the frequency of injections, the total daily dose of teriparatide was able to be reduced. Winer et al. (13) showed that twice daily teriparatide was able to reduce urine calcium concentrations, while keeping serum calcium just below the normal range throughout the day. The trial did not continue long enough to show a reduction in the risk of nephrocalcinosis (42).

Given that ADH1 is characterized by activating mutations in the CaSR, calcilytic drugs, which are negative allosteric modulators of the extracellular calcium-sensing receptor, could be ideal pharmacologic agents for treatment of ADH1. Calcilytic therapies stimulate PTH secretion and reduce renal calcium excretion. In a pilot study (56) of 5 patients with ADH1, the calcilytic drug NPSP795 was able to increase PTH in an apparent dosedependent manner. Fasting serum ionized calcium levels remained stable despite calcium and calcitriol doses being withheld. This class of drugs holds promise for treatment of patients with postsurgical hypoparathyroidism with residual parathyroid tissue.

\section{Conclusion}

Treatment of chronic hypoparathyroidism represents a significant challenge in both the clinical and research setting. The regulatory approval of adjunctive PTH(1-84) therapy in January 2015 gave patients with chronic hypoparathyroidism the option of treatment with the missing hormone for the first time in history. The availability of this treatment has stimulated the development of a range of new therapeutic options, which may eventually benefit patients with this complex disorder, and further improve their quality of life.

\section{Declaration of interest}

Dr Clarke has received research funding from Takeda/Shire, Ascendis, and Chugai Pharmaceuticals, and served as consultant to Takeda/Shire and Calcilytix.

\section{Funding}

This work did not receive any specific grant from any funding agency in the public, commercial or not-for-profit sector.

\section{References}

1 Bollerslev J, Rejnmark L, Marcocci C, Shoback DM, Sitges-Serra A, van Biesen W, Dekkers OM \& European Society of Endocrinology. European Society of Endocrinology Clinical Guideline: treatment of chronic hypoparathyroidism in adults. European Journal of Endocrinology 2015173 G1-G20. (https://doi.org/10.1530/ EJE-15-0628)

2 Brandi ML, Bilezikian JP, Shoback D, Bouillon R, Clarke BL, Thakker RV, Khan AA \& Potts Jr JT. Management of hypoparathyroidism: summary statement and guidelines. Journal of Clinical Endocrinology and Metabolism 2016101 2273-2283. (https:// doi.org/10.1210/jc.2015-3907)

3 Bollerslev J, Schalin-Jäntti C, Rejnmark L, Siggelkow H, Morreau H, Thakker R, Sitges-Serra A, Cetani F \& Marcocci C. MANAGEMENT OF ENDOCRINE DISEASE: Unmet therapeutic, educational and scientific needs in parathyroid disorders. European Journal of Endocrinology 2019 181 P1-P19. (https://doi.org/10.1530/EJE-19-0316)

4 Khan AA, Koch CA, Van Uum SHM, Baillargeon JP, Bollerslev J, Brandi ML, Marcocci C, Rejnmark L, Rizzoli R, Shrayyef MZ, et al. Standards of care for hypoparathyroidism in adults: a Canadian and international consensus. European Journal of Endocrinology 2019180 P1-P22. (https://doi.org/10.1530/ EJE-18-0609)

5 Palermo A, Naciu AM, Tabacco G, Manfrini S, Trimboli P, Vescini F \& Falchetti A. Calcium citrate: from biochemistry and physiology to clinical applications. Reviews in Endocrine and Metabolic Disorders 2019 20 353-364. (https://doi.org/10.1007/s11154-019-09520-0)

6 Harvey JA, Zobitz MM \& Pak CY. Dose dependency of calcium absorption: a comparison of calcium carbonate and calcium citrate. Journal of Bone and Mineral Research 19883 253-258. (https://doi. org/10.1002/jbmr.5650030303)

7 Bilezikian JP. Hypoparathyroidism. Journal of Clinical Endocrinology and Metabolism 2020105 1722-1736. (https://doi.org/10.1210/ clinem/dgaa113)

8 Mannstadt M, Bilezikian JP, Thakker RV, Hannan FM, Clarke BL, Rejnmark L, Mitchell DM, Vokes TJ, Winer KK \& Shoback DM. Hypoparathyroidism. Nature Reviews Disease Primers 2017317055. (https://doi.org/10.1038/nrdp.2017.55)

9 Samuels MH, Veldhuis J, Cawley C, Urban RJ, Luther M, Bauer R \& Mundy G. Pulsatile secretion of parathyroid hormone in normal young subjects: assessment by deconvolution analysis. Journal of Clinical Endocrinology and Metabolism 199377 399-403. (https://doi. org/10.1210/jcem.77.2.8345044)

10 Harms HM, Kaptaina U, Külpmann WR, Brabant G \& Hesch RD. Pulse amplitude and frequency modulation of parathyroid hormone in plasma. Journal of Clinical Endocrinology and Metabolism 198969 843-851. (https://doi.org/10.1210/jcem-69-4-843)

11 Chiavistelli S, Giustina A \& Mazziotti G. Parathyroid hormone pulsatility: physiological and clinical aspects. Bone Research 20153 14049. (https://doi.org/10.1038/boneres.2014.49)

12 Winer KK, Yanovski JA \& Cutler GB. Synthetic human parathyroid hormone 1-34 vs calcitriol and calcium in the treatment of hypoparathyroidism. JAMA 1996276 631-636. (https://doi. org/10.1001/jama.1996.03540080053029)

13 Winer KK, Yanovski JA, Sarani B \& Cutler Jr GB. A randomized, crossover trial of once-daily versus twice-daily parathyroid hormone 1-34 in treatment of hypoparathyroidism. Journal of Clinical Endocrinology and Metabolism 199883 3480-3486. (https://doi.org/10.1210/ jcem.83.10.5185)

14 Winer KK, Zhang B, Shrader JA, Peterson D, Smith M, Albert PS \& Cutler Jr GB. Synthetic human parathyroid hormone 1-34 replacement therapy: a randomized crossover trial comparing pump versus injections in the treatment of chronic hypoparathyroidism. Journal of Clinical Endocrinology and Metabolism 201297 391-399. (https://doi.org/10.1210/jc.2011-1908)

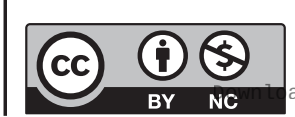

This work is licensed under a Creative Commons Attribution-NonCommercial 4.0 International License. ded from Bioscientifica com at 04/26/2023 09:52:36AM 
15 Palermo A, Santonati A, Tabacco G, Bosco D, Spada A, Pedone C, Raggiunti B, Doris T, Maggi D, Grimaldi F, et al. PTH(1-34) for surgical hypoparathyroidism: a 2-year prospective, open-label investigation of efficacy and quality of life. Journal of Clinical Endocrinology and Metabolism 2018103 271-280. (https://doi. org/10.1210/jc.2017-01555)

16 Winer KK, Ko CW, Reynolds JC, Dowdy K, Keil M, Peterson D, Gerber LH, McGarvey C \& Cutler Jr GB. Long-term treatment of hypoparathyroidism: A randomized controlled study comparing parathyroid hormone-(1-34) versus calcitriol and calcium. Journal of Clinical Endocrinology and Metabolism 200388 4214-4220. (https:// doi.org/10.1210/jc.2002-021736)

17 Santonati A, Palermo A, Maddaloni E, Bosco D, Spada A, Grimaldi F, Raggiunti B, Volpe R, Manfrini S, Vescini F, et al. PTH(1-34) for surgical hypoparathyroidism: a prospective, open-label investigation of efficacy and quality of life. Journal of Clinical Endocrinology and Metabolism 2015100 3590-3597. (https://doi.org/10.1210/jc.20151855)

18 Tuli G, Buganza R, Tessaris D, Einaudi S, Matarazzo P \& de Sanctis L. Teriparatide (rhPTH 1-34) treatment in the pediatric age: long-term efficacy and safety data in a cohort with genetic hypoparathyroidism. Endocrine 202067 457-465. (https://doi. org/10.1007/s12020-019-02128-z)

19 Winer KK, Kelly A, Johns A, Zhang B, Dowdy K, Kim L, Reynolds JC, Albert PS \& Cutler Jr GB. Long-term parathyroid hormone 1-34 replacement therapy in children with hypoparathyroidism. Journal of Pediatrics 2018203 391.e1-399.e1. (https://doi.org/10.1016/j. jpeds.2018.08.010)

20 Gafni RI, Langman CB, Guthrie LC, Brillante BA, James R, Yovetich NA, Boyce AM \& Collins MT. Hypocitraturia is an untoward side effect of synthetic human parathyroid hormone (hPTH) 1-34 therapy in hypoparathyroidism that may increase renal morbidity. Journal of Bone and Mineral Research 201833 1741-1747. (https://doi. org/10.1002/jbmr.3480)

21 Clarke BL, Kay Berg J, Fox J, Cyran JA \& Lagast H. Pharmacokinetics and pharmacodynamics of subcutaneous recombinant parathyroid hormone (1-84) in patients with hypoparathyroidism: an open-label, single-dose, phase 1 study. Clinical Therapeutics 201436 722-736. (https://doi.org/10.1016/j.clinthera.2014.04.001)

22 Sikjaer T, Amstrup AK, Rolighed L, Kjaer SG, Mosekilde L, Rejnmark L. PTH(1-84) replacement therapy in hypoparathyroidism: a randomized controlled trial on pharmacokinetic and dynamic effects after 6 months of treatment. Journal of Bone and Mineral Research 201328 2232-2243. (https://doi.org/10.1002/jbmr.1964)

23 Cusano NE \& Bilezikian JP. Treatment with Parathyroid Hormone, pp. 25-31. Berlin, Germany: Springer International Publishing, 2020.

24 Mannstadt M, Clarke BL, Vokes T, Brandi ML, Ranganath L, Fraser WD, Lakatos P, Bajnok L, Garceau R, Mosekilde L, et al. Efficacy and safety of recombinant human parathyroid hormone (1-84) in hypoparathyroidism (REPLACE): a double-blind, placebo-controlled, randomised, phase 3 study. Lancet: Diabetes and Endocrinology 20131 275-283. (https://doi.org/10.1016/S22138587(13)70106-2)

25 Bilezikian J, Bone H, Clarke B, Denham D, Lee HM, Levine M, Mannstadt M, Peacock M, Rothman J, Sherry N, et al. Safety and efficacy of recombinant human parathyroid hormone 1-84 for the treatment of adults with chronic hypoparathyroidism: sixyear results of the RACE study. Journal of the Endocrine Society 20193 (Supplement 1) abstract OR30-1. (https://doi.org/10.1210/ js.2019-OR30-1)

26 Mannstadt M, Clarke BL, Bilezikian JP, Bone H, Denham D, Levine MA, Peacock M, Rothman J, Shoback DM, Warren ML, et al. Safety and efficacy of 5 years of treatment with recombinant human parathyroid hormone in adults with hypoparathyroidism. Journal of Clinical Endocrinology and Metabolism 2019104 5136-5147. (https:// doi.org/10.1210/jc.2019-01010)
27 Lakatos P, Bajnok L, Lagast H \& Valkusz Z. An open-label extension study of parathyroid hormone rhPTH(1-84) in adults with hypoparathyroidism. Endocrine Practice 201622 523-532. (https:// doi.org/10.4158/EP15936.OR)

28 Tay YD, Tabacco G, Cusano NE, Williams J, Omeragic B, Majeed R, Gomez Almonte M, Bilezikian JP \& Rubin MR. Therapy of hypoparathyroidism with $\mathrm{rhPTH}(1-84)$ : a prospective, 8-year investigation of efficacy and safety. Journal of Clinical Endocrinology and Metabolism 2019104 5601-5610. (https://doi.org/10.1210/ jc.2019-00893)

29 Tabacco G, Tay YD, Cusano NE, Williams J, Omeragic B, Majeed R, Almonte MG, Rubin MR \& Bilezikian JP. Quality of life in hypoparathyroidism improves with $\mathrm{rhPTH}(1-84)$ throughout 8 years of therapy. Journal of Clinical Endocrinology and Metabolism 2019104 2748-2756. (https://doi.org/10.1210/jc.2018-02430)

30 Clarke BL, Vokes TJ, Bilezikian JP, Shoback DM, Lagast H \& Mannstadt M. Effects of parathyroid hormone rhPTH(1-84) on phosphate homeostasis and vitamin D metabolism in hypoparathyroidism: REPLACE phase 3 study. Endocrine 201755 273-282. (https://doi.org/10.1007/s12020-016-1141-0)

31 Chen KS, Gosmanova EO, Curhan GC, Ketteler M, Rubin M, Swallow E, Zhao J, Wang J, Sherry N, Krasner A, et al. 5 -year estimated glomerular filtration rate in patients with hypoparathyroidism treated with and without rhPTH. Journal of Clinical Endocrinology and Metabolism 2020105 dgaa490. (https://doi. org/10.1210/clinem/dgaa490)

32 Bilezikian JP, Clarke BL, Mannstadt M, Rothman J, Vokes T, Lee HM \& Krasner A. Safety and efficacy of recombinant human parathyroid hormone in adults with hypoparathyroidism randomly assigned to receive fixed $25-\mu \mathrm{g}$ or $50-\mu \mathrm{g}$ daily doses. Clinical Therapeutics 201739 2096-2102. (https://doi.org/10.1016/j. clinthera.2017.08.011)

33 Clarke BL, Rejnmark L, Ing SW, Brandi ML, Björnsdottir S, Hofbauer LC, Houillier P, Khan AA, Levine MA, Mannstadt M, et al. Baseline characteristics from the observational PARADIGHM registry of patients with chronic hypoparathyroidism. Journal of the Endocrine Society 20204 (Supplement 1) abstract SAT-399. (https:// doi.org/10.1210/jendso/bvaa046.591)

34 Cusano NE, Rubin MR, McMahon DJ, Irani D, Anderson L, Levy E, Bilezikian JP. PTH(1-84) is associated with improved quality of life in hypoparathyroidism through 5 years of therapy. Journal of Clinical Endocrinology and Metabolism 201499 3694-3699. (https://doi. org/10.1210/jc.2014-2267)

35 Vokes TJ, Mannstadt M, Levine MA, Clarke BL, Lakatos P, Chen K, Piccolo R, Krasner A, Shoback DM \& Bilezikian JP. Recombinant human parathyroid hormone effect on health-related quality of life in adults with chronic hypoparathyroidism. Journal of Clinical Endocrinology and Metabolism 2018103 722-731. (https://doi. org/10.1210/jc.2017-01471)

36 Sikjaer T, Rolighed L, Hess A, Fuglsang-Frederiksen A, Mosekilde L \& Rejnmark L. Effects of PTH(1-84) therapy on muscle function and quality of life in hypoparathyroidism: results from a randomized controlled trial. Osteoporosis International 201425 1717-1726. (https://doi.org/10.1007/s00198-014-2677-6)

37 Wilde D, Wilken L, Stamm B, Heppner C, Leha A, Blaschke M, Herrmann-Lingen C \& Siggelkow H. Quantification of symptom load by a disease-specific questionnaire HPQ 28 and analysis of associated biochemical parameters in patients with postsurgical hypoparathyroidism. JBMR Plus 20204 e10368. (https://doi. org/10.1002/jbm4.10368)

38 Gafni RI, Guthrie LC, Kelly MH, Brillante BA, Christie CM, Reynolds JC, Yovetich NA, James R \& Collins MT. Transient increased calcium and calcitriol requirements after discontinuation of human synthetic parathyroid hormone 1-34 (hPTH 1-34) replacement therapy in hypoparathyroidism. Journal of Bone and Mineral Research 201530 2112-2118. (https://doi.org/10.1002/jbmr.2555)

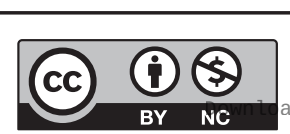

This work is licensed under a Creative Commons Attribution-NonCommercial 4.0 International License. ded from Bioscientifica.com at 04/26/2023 09:52:36AM 
39 Tecilazich F, Formenti AM, Frara S, Giubbini R \& Giustina A. Treatment of hypoparathyroidism. Best Practice and Research: Clinical Endocrinology and Metabolism 201832 955-964. (https://doi. org/10.1016/j.beem.2018.12.002)

40 Vahle JL, Sato M, Long GG, Young JK, Francis PC, Engelhardt JA, Westmore MS, Linda Y \& Nold JB. Skeletal changes in rats given daily subcutaneous injections of recombinant human parathyroid hormone (1-34) for 2 years and relevance to human safety. Toxicologic Pathology 200230 312-321. (https://doi. org/10.1080/01926230252929882)

41 Jolette J, Wilker CE, Smith SY, Doyle N, Hardisty JF, Metcalfe AJ, Marriott TB, Fox J \& Wells DS. Defining a noncarcinogenic dose of recombinant human parathyroid hormone $1-84$ in a 2-year study in Fischer 344 rats. Toxicologic Pathology 200634 929-940. (https://doi. org/10.1080/01926230601072301)

42 Tabacco G \& Bilezikian JP. New directions in treatment of hypoparathyroidism. Endocrinology and Metabolism Clinics of North America 201847 901-915. (https://doi.org/10.1016/j. ecl.2018.07.013)

43 Gafni RI, Brahim JS, Andreopoulou P, Bhattacharyya N, Kelly MH, Brillante BA, Reynolds JC, Zhou H, Dempster DW \& Collins MT. Daily parathyroid hormone 1-34 replacement therapy for hypoparathyroidism induces marked changes in bone turnover and structure. Journal of Bone and Mineral Research 201227 1811-1820. (https://doi.org/10.1002/jbmr.1627)

44 Rejnmark L, Sikjaer T, Underbjerg L \& Mosekilde L. PTH replacement therapy of hypoparathyroidism. Osteoporosis International 201324 1529-1536. (https://doi.org/10.1007/s00198-012-2230-4)

45 Cusano NE, Rubin MR, Williams JM, Agarwal S, Tabacco G, Tay D, Majeed R, Omeragic B \& Bilezikian JP. Changes in skeletal microstructure through four continuous years of $\operatorname{rhPTH}(1-84)$ therapy in hypoparathyroidism. Journal of Bone and Mineral Research 202035 1274-1281. (https://doi.org/10.1002/jbmr.4005)

46 Holten-Andersen L, Pihl S, Rasmussen CE, Zettler J, Maitro G, Baron J, Heinig S, Hoffmann E, Wegge T, Krusch M, et al. Design and preclinical development of TransCon PTH, an investigational sustained-release PTH replacement therapy for hypoparathyroidism. Journal of Bone and Mineral Research 01934 2075-2086. (https://doi. org/10.1002/jbmr.3824)

47 Karpf DB, Pihl S, Mourya S, Mortensen E, Kovoor E, Markova D $\&$ Leff JA. A randomized double-blind placebo-controlled first-inhuman phase 1 trial of TransCon PTH in healthy adults. Journal of Bone and Mineral Research 202035 1430-1440. (https://doi. org/10.1002/jbmr.4016)

48 Khan AA, Rejnmark L, Schwarz PE, Vokes TJ, Clarke BL, Rubin MR, Hofbauer LC, Erikson E, Palermo A, Pagotto U, et al. Design of the
PaTH forward phase 2 trial of TransCon PTH, a long-acting PTH, in patients with hypoparathyroidism. Journal of the Endocrine Society 20204 (Supplement 1) abstract SAT-LB72. (https://doi.org/10.1210/ jendso/bvaa046.2209)

49 Guo J, Khatri A, Maeda A, Potts JT, Jüppner H \& Gardella TJ. Prolonged pharmacokinetic and pharmacodynamic actions of a pegylated parathyroid hormone (1-34) peptide fragment. Journal of Bone and Mineral Research 201732 86-98. (https://doi.org/10.1002/ jbmr.2917)

50 Shimizu M, Joyashiki E, Noda H, Watanabe T, Okazaki M, Nagayasu M, Adachi K, Tamura T, Potts JT Jr, Gardella TJ, et al. Pharmacodynamic actions of a long-acting PTH analog (LA-PTH) in thyroparathyroidectomized (TPTX) rats and normal monkeys. Journal of Bone and Mineral Research 201631 1405-1412. (https://doi. org/10.1002/jbmr.2811)

51 Bi R, Fan Y, Lauter K, Hu J, Watanabe T, Cradock J, Yuan Q, Gardella T \& Mannstadt M. Diphtheria toxin- and GFP-based mouse models of acquired hypoparathyroidism and treatment with a long-acting parathyroid hormone analog. Journal of Bone and Mineral Research 201631 975-984. (https://doi.org/10.1002/ jbmr.2769)

52 Krishnan V, Ma YL, Chen CZ, Thorne N, Bullock H, Tawa G, Javella-Cauley C, Chu S, Li W, Kohn W, et al. Repurposing a novel parathyroid hormone analogue to treat hypoparathyroidism. British Journal of Pharmacology 2018175 262-271. (https://doi.org/10.1111/ bph.14028)

53 Tamura T, Noda H, Joyashiki E, Hoshino M, Watanabe T, Kinosaki M, Nishimura Y, Esaki T, Ogawa K, Miyake T, et al. Identification of an orally active small-molecule PTHR1 agonist for the treatment of hypoparathyroidism. Nature Communications 20167 13384. (https:// doi.org/10.1038/ncomms13384)

54 Khan AA, Clarke B, Rejnmark L \& Brandi ML. Management of endocrine disease: hypoparathyroidism in pregnancy: review and evidence-based recommendations for management. European Journal of Endocrinology 2019180 R37-R44. (https://doi.org/10.1530/EJE-180541)

55 Palermo A, Mangiameli G, Tabacco G, Longo F, Pedone C, Briganti SI, Maggi D, Vescini F, Naciu A, Lauria Pantano A, et al. PTH(1-34) for the primary prevention of postthyroidectomy hypocalcemia: the THYPOS trial. Journal of Clinical Endocrinology and Metabolism 2016 101 4039-4045. (https://doi.org/10.1210/jc.2016-2530)

56 Roberts MS, Gafni RI, Brillante B, Guthrie LC, Streit J, Gash D, Gelb J, Krusinska E, Brennan SC, Schepelmann M, et al. Treatment of autosomal dominant hypocalcemia type 1 with the calcilytic NPSP795 (SHP635). Journal of Bone and Mineral Research 201934 1609-1618. (https://doi.org/10.1002/jbmr.3747)

Received in final form 11 September 2020

Accepted 24 September 2020

Accepted Manuscript published online 25 September 2020 https://ec.bioscientifica.com https://doi.org/10.1530/EC-20-0366 (c) 2020 The authors Published by Bioscientifica Ltd

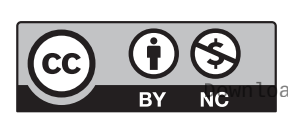

This work is licensed under a Creative Commons Attribution-NonCommercial 4.0 International License. ded from Bioscientifica.com at 04/26/2023 09:52:36AM 